Conclusion: Prevalence of COVID-19 symptoms and confirmed cases was similar between diseases, and for symptoms, was not associated with treatment. Despite strong advice from health authorities, less than $50 \%$ of patients with inflammatory rheumatic diseases and COVID-19 symptoms were tested. This proportion was not significantly different between diseases and not influenced by type of treatment. Efforts should be made to improve rates of SARS-CoV2 testing in patients with rheumatic diseases.

REFERENCES:

[1] Williamson, E. J. et al. Factors associated with COVID-19-related death using OpenSAFELY. Nature 584, 430-436 (2020).

Acknowledgements: This study was supported by Pfizer, Sanofi, Novartis, Gilead, Biogen and Bristol-Myers Squibb.

We thank all the patients and health professionals contributing to SCQM.

Disclosure of Interests: Eleftherios Papagiannoulis: None declared, Adrian Ciurea Speakers bureau: Abbvie, Eli Lilly, MSD, Novartis, Pfizer, Diana Dan: None declared, Axel Finckh: None declared, Benoit GILBERT: None declared, Isabell von Loga Consultant of: Deloitte Consulting AG., Cathy Melong Pianta Taleng: None declared, Almut Scherer Consultant of: Pfizer, Employee of: BMS (2007-2008), Kim Lauper Consultant of: Gilead Galapagos, Grant/research support from: AbbVie. The SCQM foundation is supported by different companies https://www.scqm.ch/en/sponsoren/.

DOI: 10.1136/annrheumdis-2021-eular.683

\section{POS1169 IMPACT OF THE COVID-19 PANDEMIC ON MORBIDITY AND MORTALITY AMONG SWEDISH PATIENTS WITH INFLAMMATORY JOINT DISEASES VERSUS THE GENERAL POPULATION}

H. Bower ${ }^{1}$, T. Frisell ${ }^{1}$, D. DI Giuseppe ${ }^{1}$, B. Delcoigne ${ }^{1}$, G. M. Alenius ${ }^{2}$ E. Baecklund $^{3}$, K. Chatzidionysiou', N. Feltelius ${ }^{4}$, H. Forsblad-D'elia ${ }^{5}$, A. Kastbom ${ }^{6}$, L. Klareskog ${ }^{1}$, E. Lindqvist ${ }^{7}$, U. Lindström ${ }^{5}$, C. Turesson ${ }^{8}$, C. Sjowall ${ }^{5}$, J. Askling ${ }^{1}{ }^{1}$ Karolinska Institutet, Department of Medicine Solna, Division of Clinical Epidemiology, Stockholm, Sweden: ${ }^{2}$ Umeå University, Rheumatology Unit, Department of Public Health and Clinical Medicine, Umeå, Sweden; ${ }^{3}$ Uppsala University, Department of Medical Sciences, Uppsala, Sweden; ${ }^{4}$ Swedish Medical Products Agency, Swedish Medical Products Agency, Uppsala, Sweden; ${ }^{5}$ Sahlgrenska Academy, University of Gothenburg, Department of Rheumatology and Inflammation Research, Gothenburg, Sweden; ${ }^{6}$ Linköping University, Department of Biomedical and Clinical Sciences, Linköping, Sweden; ${ }^{7}$ Skåne University Hospital, Lund University, Department of Clinical Sciences, Rheumatology, Lund, Sweden; ${ }^{8}$ Lund University, Rheumatology, Department of Clinical Sciences, Malmö, Sweden

Background: Studies from COVID-19 case-repositories among patients with rheumatic diseases have assessed associations (relative risks) between characteristics of the disease and adverse COVID-19 outcomes. Such designs are susceptible to bias from selection of cases reported. Few studies have assessed absolute and relative risks for COVID-19 outcomes in population-based cohorts of patients with inflammatory joint diseases, nor compared these risks to those in the general population.

Objectives: To estimate all-cause mortality, absolute and relative risks for severe COVID-19 in patients with chronic inflammatory joint diseases, compared over time and to the general population.

Methods: We updated a multi-register nationwide linkage ("ARTIS") on adults with RA, PsA, AS, SpA or JIA and population referents (matched on sex, age, and region), with data on hospitalizations, admission to intensive care (ICU), and deaths due to COVID-19. We calculated all-cause mortality March-September 2015-2020, and absolute and relative risks for COVID-19 outcomes March-September 2020. Patients were compared to population referents using hazard ratios (HR) from Cox models adjusted for comorbidities and socio-economy.

Results: We identified 110567 individuals with inflammatory joint disease (53455 with RA) in Sweden on March $1^{\text {st }} 2020$, and 484277 matched general population subjects. In all cohorts, the absolute risk of death from any cause in 2020 was higher than 2015-2019 (Figure 1), with a peak in mid-April, but the relative risks of death (vs. the general population) 2020 remained similar to HRs for 2015-2019 (HR for 2020 in Table 1).

Among all individuals with inflammatory joint disease in 2020, the risk for hospitalization, admission to ICU, and death due to COVID-19 was $0.5 \%$, $0.04 \%$ and $0.1 \%$, respectively (Table 1 ). HRs (vs. the general population) were elevated for almost all outcomes. HRs for COVID-19 related outcomes (Table 1) were higher than for non-COVID-19 outcomes; adjustment for co-morbidities and socio-economy explained much of these increases, somewhat less so for the former.

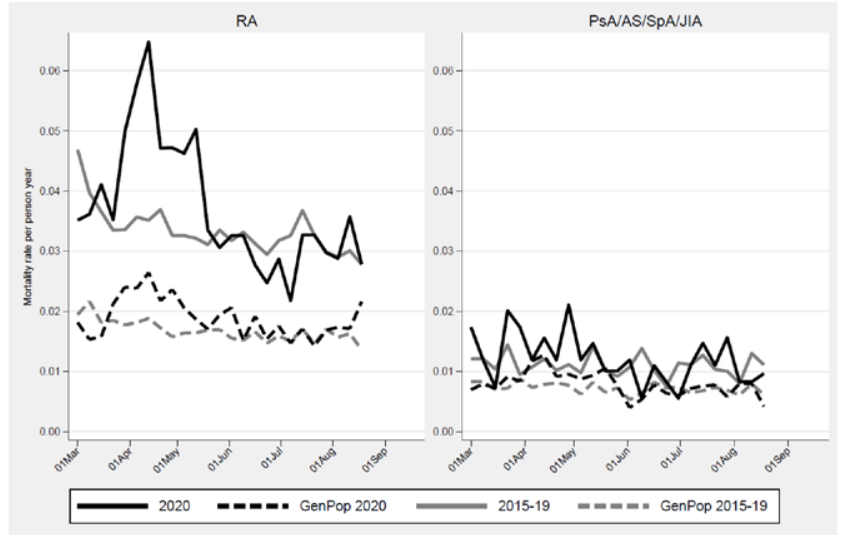

Figure 1. All-cause mortality in Swedish individuals with inflammatory joint disease and general population, March-September 2020 and the average 2015-2019

Table 1. Absolute and relative risks for COVID-19 outcomes in Swedish individuals with inflammatory joint disease compared to general population comparators March-September 2020

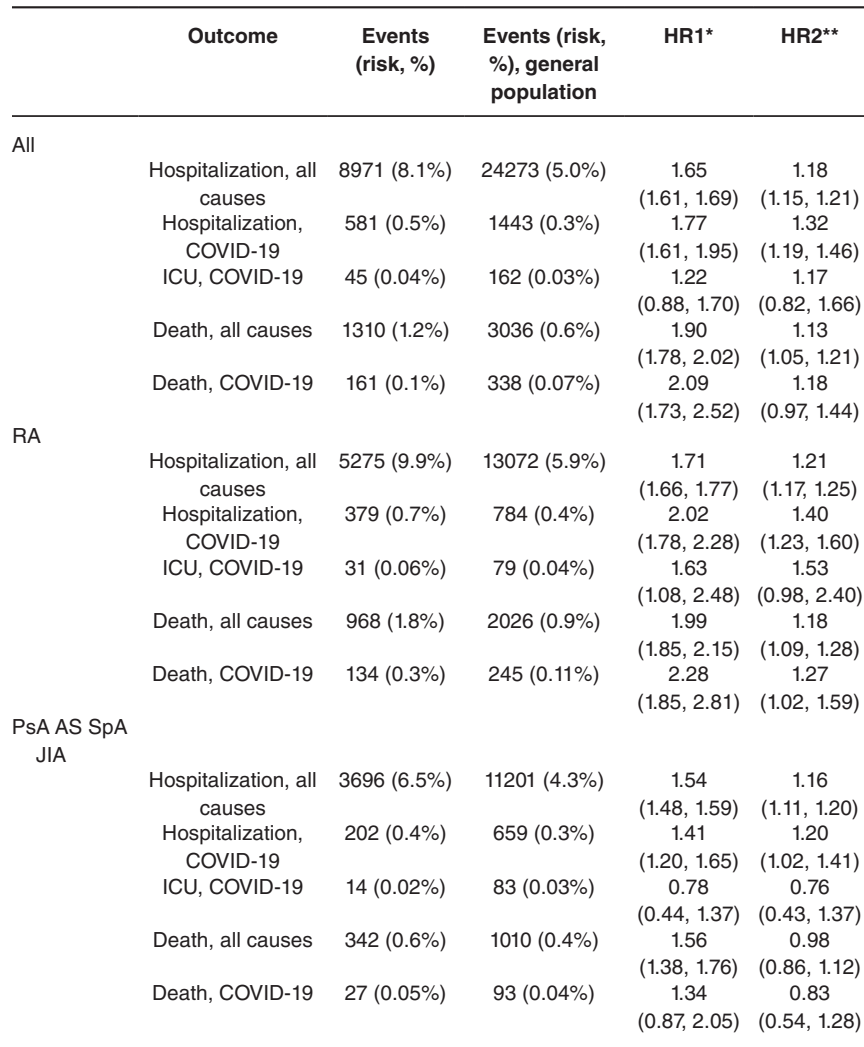

${ }^{*} \mathrm{HR} 1$ unadjusted, matched (age, sex, and region) ${ }^{\star *} \mathrm{HR} 2$, as HR1 but adjusted for comorbidities and socio-economy

Conclusion: Risks of severe COVID-19 were increased among patients with inflammatory joint diseases, but similar increases were seen for non-COVID-19 morbidity. Co-morbidities and socio-economy explain much of this increase.

Disclosure of Interests: Hannah Bower: None declared, Thomas Frisell: None declared, Daniela Di Giuseppe: None declared, Bénédicte Delcoigne: None declared, Gerd-Marie Alenius: None declared, Eva Baecklund: None declared, Katerina Chatzidionysiou Speakers bureau: Eli Lilly, AbbVie and Pfizer, Consultant of: Eli Lilly, AbbVie and Pfizer, Nils Feltelius Employee of: Nils Feltelius is employed by the Medical Products Agency (MPA), which is a governmental body. The views in this abstract may not represent the views of the MPA, Helena Forsblad-d'Elia: None declared, Alf Kastbom Employee of: Former employee of Sanofi, Lars Klareskog: None declared, Elisabet Lindqvist: None declared, Ulf Lindström: None declared, Carl Turesson Speakers bureau: Roche, AbbVie and 
Pfizer, Consultant of: Roche, Grant/research support from: Research grant from Bristol-Myers Squibb, Christopher Sjowall: None declared, Johan Askling Grant/ research support from: PI for agreements between Karolinska Institutet and Abbvie, BMS, Eli Lilly, Pfizer, Roche, Samsung Bioepis, and Sanofi for safety monitoring of anti-rheumatic therapies (ARTIS).

DOI: 10.1136/annrheumdis-2021-eular.685

\section{POS1170 SELF-PROTECTION STRATEGIES, HEALTH BEHAVIOR AND DISEASE ACTIVITY DURING THE FIRST WAVE, RE-OPENING AND SECOND WAVE OF THE COVID- 19 PANDEMIC IN > 7000 DANISH PATIENTS WITH INFLAMMATORY ARTHRITIS}

B. Glintborg ${ }^{1}$, D. V. Jensen ${ }^{2}$, S. Engel ${ }^{1}$, L. Terslev ${ }^{1}$, M. Pfeiffer Jensen ${ }^{1}$,

O. Hendricks ${ }^{3}$, M. Østergaard ${ }^{1}$, S. H. Rasmussen 1 , T. Adelsten ${ }^{4}$, K. Danebod ${ }^{1}$ A. Colic ${ }^{4}$, M. Kildemand ${ }^{5}$, A. G. Loft ${ }^{6}$, H. L. Munk ${ }^{5}$, J. K. Pedersen ${ }^{7}$, R. Østgård ${ }^{8}$, C. M. Sørensen ${ }^{9}$, N. Steen $\mathrm{Krogh}^{10}$, J. Nørgaard Agerbo ${ }^{11}$, C. Ziegler ${ }^{11}$, M. L. Hetland ${ }^{1}{ }^{1}$ Center for Rheumatology and Spine Diseases, Centre of Head and Orthopedics, DANBIO and Copenhagen Center for Arthritis Research (COPECARE), Copenhagen, Denmark; ${ }^{2}$ Center for Rheumatology and Spine Diseases Gentofte and Herlev Hospital, Department of Rheumatology, Gentofte, Denmark; ${ }^{3}$ University Hospital of Southern Denmark, Danish Hospital for Rheumatic Diseases, Sønderborg, Denmark; ${ }^{4}$ Zealand University Hospital, Department of Rheumatology, Køge, Denmark; ${ }^{5}$ Odense University Hospital, Department of Rheumatology, Odense, Denmark; ${ }^{6}$ Aarhus University Hospital, Department of Rheumatology, Aarhus, Denmark; ${ }^{7}$ Odense University Hospital and Svendborg Hospital, Department of Rheumatology, Odense, Denmark; ${ }^{8}$ Silkeborg Regional Hospital, Diagnostic Center, Silkeborg, Denmark; ${ }^{9}$ Horsens Regional Hospital, Department of Medicine, Horsens, Denmark; ${ }^{10}$ ZiteLab Aps, Copenhagen, Denmark; ${ }^{11}$ Gigtforeningen/Danish Rheumatism Association, - , Copenhagen, Denmark

Background: The COVID-19 pandemic has caused lockdown, reduced access to face-to-face consultations, anxiety about taking immunosuppressive agents and self-isolation ${ }^{1}$ which potentially impact rheumatic disease control negatively. However, changes in behavior including self-protection strategies during the ongoing pandemic and impact on rheumatic disease activity have only been scarcely described.

The first COVID-19 wave hit Denmark in March 2020 followed by a gradual re-opening from mid-April and the second surge began in the late autumn of 2020.

Objectives: To describe changes over time in self-protection strategies and health behavior during the first 8 months of the COVID-19 pandemic and to explore impact on self-reported disease activity and quality of life (=patient reported outcomes, PROs) in patients with inflammatory rheumatic disease (IRD) in DANBIO.

Methods: Patients were invited to answer two on-line questionnaires regarding current behavior and disease specific PROs: One in June 2020 (including also questions regarding behavior in March 2020), and one in November 2020. Responses were linked to PROs collected as part of routine care before March 2020 (=Before) in DANBIO. For each PRO, changes (=delta values) between the two timepoints were calculated in individual patients.

Results: Overall, 7,836 patients (22\% of eligible patients) answered both questionnaires and were included (rheumatoid arthritis(RA): $5270(67 \%)$, psoriatic arthritis(PsA): 1217(15\%), axial spondyloarthritis(AxSpA): 932(12\%), other IRD: $417(5 \%)$. Patients reported highest levels of anxiety and self-protection in March with an improvement in June that was largely unchanged in November (Figure 1), e.g. proportions staying at home avoiding others as much as possible (completely or mostly agree) were $87 \% / 49 \% / 51 \%$ in March/June/November, respectively (Figure 1, Panel C).

Disease activity and proportions of patients reporting acceptable symptom state remained stable at the three time points (Table 1), with all median delta values being close to zero (not shown).

Conclusion: In this large cohort of patients with inflammatory rheumatic diseases followed in the nationwide DANBIO registry, COVID-19 related self-protection strategies were highest in March 2020, but more than half of the patients also reported self-isolation in June and November. We found no negative impact of the pandemic on patient-reported outcomes, which remained largely unchanged and were similar to before the pandemic. The latter finding probably reflects that few patients reduced or withdrew from treatment due to fear of COVID-19.
REFERENCES:

[1] Glintborg et al, 2021, https://rmdopen.bmj.com/content/rmdopen/7/1/ e001505.full.pdf

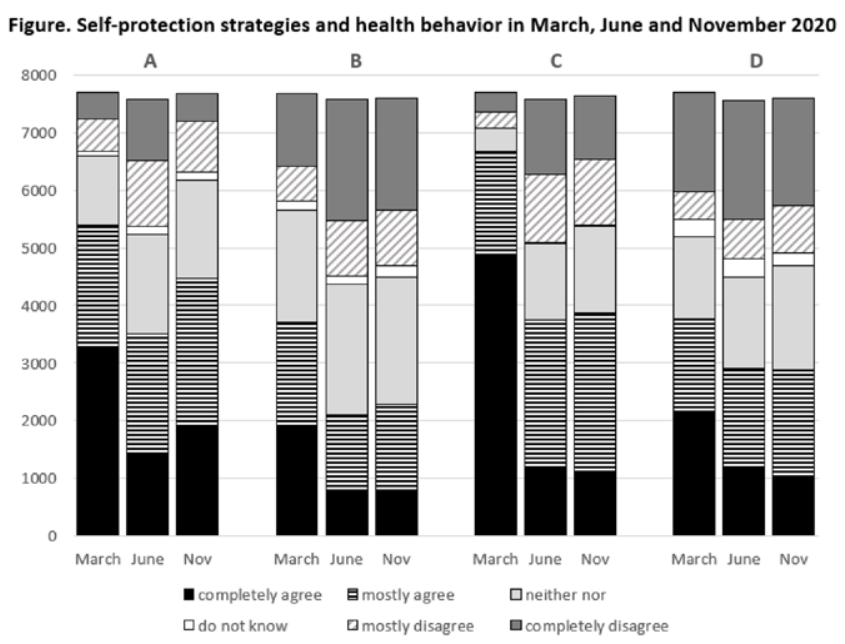

A: I consider myself at high risk of COVID-19 infection. B: I worry more about COVID-19 than about my rheumatic disease. C: I stay at home and avoid others as much as possible. D: My arthritis causes me to self-isolate more than others my age

Table 1. Patient reported outcomes before March, in June and in November 2020 in patients with IRD. $\mathrm{N}=7,836$

\begin{tabular}{lccc}
\hline & Before $^{\star}$ & June 2020 & Nov 2020 \\
\hline Patient VAS global, mm & $30(12-58)$ & $28(10-54)$ & $29(10-55)$ \\
Patient VAS pain, mm & $27(11-51)$ & $28(11-51)$ & $29(11-52)$ \\
HAQ & $0.50(0.13-1.0)$ & $0.50(0.13-1.00)$ & $0.50(0.13-1.00)$ \\
EQ-5D & $0.80(0.72-0.86)$ & $0.79(0.71-0.86)$ & $0.80(0.71-0.86)$ \\
PASS, yes & $73 \%$ & $75 \%$ & $76 \%$
\end{tabular}

Numbers are median (IQR) unless otherwise stated ${ }^{*}$ Latest registration in DANBIO before March 2020Patient characteristics for RA/AxSpA/PsA/Other: female, \%: 70/53/44/69. Age, years, median(IQR): 67(59-74)/62(54-69)/56(46-65)/59(50-68)Abbreviations: EQ-5D: Quality of life, 5 dimensions, HAQ: health assessment questionnaire, PASS: patient acceptable symptom state, VAS: visual analogue scale

Disclosure of Interests: Bente Glintborg Grant/research support from: AbbVie, BMS, Pfizer, Dorte Vendelbo Jensen: None declared, Sara Engel: None declared, Lene Terslev Speakers bureau: AbbVie, Janssen, Roche, Novartis, Pfizer, MSD, BMS and GE, Mogens Pfeiffer Jensen: None declared, Oliver Hendricks Grant/research support from: AbbVie, Novartis, Pfizer, Mikkel Østergaard Speakers bureau: Abbvie, BMS, Boehringer-Ingelheim, Celgene, Eli-Lilly, Hospira, Janssen, Merck, Novartis, Novo, Orion, Pfizer, Regeneron, Roche, Sandoz, Sanofi and UCB., Grant/research support from: Research grants: Abbvie, BMS Celgene, Merck, Novartis, Simon Horskjær Rasmussen: None declared, Thomas Adelsten: None declared, Kamilla Danebod: None declared, Ada Colic: None declared, Malene Kildemand: None declared, Anne Gitte Loft Speakers bureau: AbbVie, Eli-Lilly, Janssen, MSD, Novartis, Pfizer, and UCB, Heidi Lausten Munk: None declared, Jens Kristian Pedersen: None declared, René Østgård Speakers bureau: Abbvie, BMS, Boehringer-Ingelheim, Eli-Lilly, Janssen, Merck, Novar tis, Pfizer, Roche, Sanofi and UCB., Grant/research support from: Research grants: Abbvie, Christian Møller Sørensen: None declared, Niels Steen Krogh None declared, Jette Nørgaard Agerbo: None declared, Connie Ziegler: None declared, Merete L. Hetland Grant/research support from:: AbbVie, Biogen, BMS, Celtrion, Eli Lilly Denmark A/S, Janssen Biologics B.V, Lundbeck Fonden, MSD Pfizer, Roche, Samsung Biopis, Sandoz. MLH chairs the steering committee of the Danish Rheumatology Quality Registry (DANBIO), which receives public funding from the hospital owners and funding from pharmaceutical companies. $\mathrm{MLH}$ co-chairs the EuroSpA research collaboration, which generates real-world evidence of treatment of psoriatic arthritis and axial spondylorthritis based on secondary data and is partly funded by Novartis. DOI: 10.1136/annrheumdis-2021-eular 722 